Boise State University

ScholarWorks

Criminal Justice Faculty Publications and

Presentations

Criminal Justice Program

4-2020

\title{
'Not Feeling Like a Caged Animal': Prisoner Perceptions of a Remote Video Visitation System
}

Danielle J. Murdoch

Simon Fraser University

Laura L. King

Boise State University

This is an Accepted Manuscript of an Article published in Journal of Crime and Justice on April 2020, available online: https://doi.org/10.1080/0735648X.2019.1653216 


\section{'Not Feeling Like a Caged Animal:' Inmate Perceptions of a Remote Inmate Video Visitation System}

\author{
Danielle J. Murdoch* \\ School of Criminology \\ Simon Fraser University \\ Burnaby, BC, Canada \\ dmurdoch@sfu.ca
}

\author{
Laura L. King \\ Department of Criminal Justice \\ Boise State University \\ Boise, ID, United States \\ lauraking2@boisestate.edu
}

Danielle J. Murdoch, Ph.D. is a Lecturer in the School of Criminology at Simon Fraser University where she teaches courses in corrections and women and justice. Her research focuses on correctional policy and practice and pedagogy.

Laura L. King, Ph.D. is an Associate Professor of Criminal Justice at Boise State University where she teaches courses in research methods, statistics, and victimology. Her research focuses on sexual violence, victimology, gender and crime, survey methodology, and quantitative analysis.

In recent years, correctional agencies have increased their use of video visitation in an effort to offset costs and increase security, among other objectives. In the present study, interviews $(\mathrm{N}=12)$ and surveys $(\mathrm{N}=58)$ were conducted with prisoners at a jail in the Northwestern U.S. that had replaced in-person, glass partition visitation with remote video visitation. The results suggested that while there were positive aspects of video visitation, such as the ability to visit with loved ones from afar, there were criticisms as well, including technological and access issues. The policy implications of the findings and directions for future research on video visitation are discussed.

Keywords: video visitation; visitation; prisoners

\section{Introduction}

The rate of incarceration in the US quadrupled from 1972 to 2007 when it reached its peak at 767 per 100,000 (Travis, Western, and Redburn 2014). While the rate of incarceration has decreased since that time, sitting at 670 per 100,000, 2.2 million individuals were imprisoned across the US in 2016 (Kaeble and Cowhig 2018). Estimates put the cost of this mass incarceration for the government and the families of those incarcerated at $\$ 182$ billion annually (Wagner and Rabuy 2017). To curb the expenditures associated with incarceration, many states have implemented criminal justice reforms designed to reduce costs and recidivism and promote public safety (Lawrence 2017).

At the institutional level, some correctional authorities have turned to video visitation as a means of reducing costs that result from providing prisoners with access to in-person visitation (Fulcher 2014). Visitation modalities vary by jurisdiction and institution type and have evolved over the years to include in-person, open visits (most common in state and federal prisons [Arditti 2003]), in-person visits conducted behind a glass partition (common in jail environments), and video visits (Fulcher 2014).

While research has examined the relationship between in-person visitation and offender conduct within the institution and upon release, there is less peer-reviewed literature examining the visitation needs of incarcerated populations (Pierce 2015), the effects of various forms of contact on incarcerated parents, their children, and their relationship, the familial processes and quality that characterize visits between children and their parents (Arditti 2012; Benning and Lahm 2016; Brunton-Smith and McCarthy 2016; Tasca, Mulvey and Rodriguez 2016), and video visitation (Digard et al. 2016; Loper and Coleman 2014). Further, researchers often examine prisons, devoting less attention to the study of jails (Sturges 2002; Sturges and Al-Khattar 2009).

The current study contributes to the limited body of literature examining video visitation and visitation practices in jails with an examination of one of the first remote video visitation systems developed and implemented in North America. The study is conducted from the perspective of prisoners, a group whose voice has typically been excluded 
This is an author-produced, peer-reviewed version of this article. The final, definitive version of this document can be found online at Journal of Crime \& Justice, published by Taylor and Francis. Copyright restrictions may apply. https://doi.org/10.1080/0735648X.2019.1653216. The content of this document may vary from the final published version.

in research examining video visitation. Their exclusion is problematic as existing gray literature that includes prisoner accounts on video visitation has described their dissatisfaction with the quality of their visits and their low use of the service due to high costs and inconvenient access to institutional kiosks, among other issues (Digard et al. 2016; Rabuy and Wagner 2015; Struges and Al-Khattar 2009). This study thus sheds light on an understudied area of visitation by exploring the visitation needs of individuals incarcerated in jail and their perceptions of the effect of video visitation on their behavior (effects that might be unique to video visitation). The findings have the potential to inform policy and practice by addressing how video visitation systems can be implemented to promote inclusivity in their use and incentivize prisoner behavior, amongst other objectives. Prior to presenting the results, we provide an overview of the literature documenting the advantages and disadvantages of in-person visitation and contextualize our study within the limited body of literature - primarily anecdotal - describing the advantages and disadvantages of video visitation.

\section{Literature Review}

\section{$\underline{\text { In-Person Visitation }}$}

There is strong theoretical support (see e.g., Agnew 1992) for providing prisoners with access to visitation to build and/or maintain social bonds and pro-social ties in an effort to reduce institutional misconduct and recidivism. There is also empirical support for this practice; to illustrate, Liu, Pickett, and Baker (2014) found in-person visitation contributed to the maintenance of social ties and social capital and that social ties were less likely to be weakened when the prevalence, frequency, and diversity of visits was high. Research also demonstrates that providing prisoners with frequent access to visitation improves the emotional support and familial interactions they experience upon release (Mowen and Visher 2016) and that it is the quality of visitation that is most important in fostering the parentchild relationship (Beckmeyer and Arditti 2014). Prison visitation has also been described as an opportunity to "reset" family relations because in-person visits provide families with the opportunity to engage in family time, strengthen the bond between children and their incarcerated parent, declare family responsibilities, and promote messages of reform (Tasca, Mulvey and Rodriguez 2016, 473).

Research examining the relationship between in-person visitation and institutional misconduct is somewhat mixed. For example, Cochran (2012) found that prisoners who did not receive visits were more likely than prisoners who received visits to engage in institutional misconduct. Cochran (2012) also reported that prisoners who received visits early on in their sentences but received fewer visits, or none as time went on, were more likely to engage in misconduct. Siennick, Mears, and Bales (2012) found the probability of a disciplinary infraction decreased in the three-week period preceding a visit, increased in the week after a visit, and steadily reached normal levels approximately six weeks after a visit. In contrast, Hensley, Koscheski, and Tewksbury (2002) did not find a significant difference in the self-reported threats of violence and use of actual violence amongst prisoners who participated in conjugal visits versus those who did not. Similarly, Jiang and Winfree (2006) and Jiang, Fisher-Giorlando, and Mo (2005) did not find that in-person visitation led to decreases in institutional infractions. Interestingly, some studies have found that visits from children increase the likelihood of offenders engaging in certain types of institutional misconduct (Benning and Lahm 2016; Jiang, Fisher-Giorlando, and Mo 2005).

Bales and Mears (2008) conducted one of the most methodologically robust studies to date and found that offenders who received any type of visitation, more frequent visitation, and visitation closer to one's release date, were less likely to recidivate. Other studies have shown that visitation closer to one's release (Derkzen, Gobeil, and Gileno 2009; Duwe and Clark 2013) and visitation that starts early in one's sentence and continues consistently throughout it (Cochran 2014) decrease recidivism. Frequent visits (Derkzen et al. 2009), visits with spouses or significant others (Derkzen et al. 2009; Mears et al. 2012), parents, children (Derkzen, Gobeil, and Gileno 2009), friends (Mears et al. 2012), siblings, in-laws, fathers, clergy (Duwe and Clark 2013), community volunteers (Duwe and Johnson 2016), and private family visits (also known as conjugal visits; Derken et al. 2009; Mitchell, Spooner, and Zhang 2016), have been found to decrease the likelihood of readmission while visits from ex-spouses have been found to increase the likelihood of recidivism (Duwe and Clark 2013). Recent research examining "how visitation matters" using the lens of social support theory offers insight about why the results from previous studies examining the effects of visits on prisoners are mixed (Meyers, Wright, Young, and Tasca 2017, 58). Visitors differ in the critical support they offer during visits, certain prisoner groups are more likely to receive supportive visits than others, and prisoners perceive supportive visitors as being more likely to provide them with support upon release, which are all factors that can affect prisoner behavior (Meyers, Wright, Young, and Tasca 2017). 
In-person visitation has also been found to contribute to prisoners' and their family members' mental health (Hairston 1991) and to affect a prisoner's perception of prison conditions, including prisoners being more likely to perceive the institution as crowded when they have had fewer visits (Wooldredge 1997). It has also been found to counteract the negative effects of imprisonment, providing "a buffer against the sometimes stressful and oppressive prison environment" (Dixey and Roodall 2012, 37). Casey-Acevedo and Bakken (2002) found support for visitation with participants believing it helps female prisoners cope with their separation from their loved ones and that it will contribute to their success upon release.

Despite the potential advantages of in-person visitation, there are a number of disadvantages as well. Existing research typically describes visitation rooms as noisy, lacking in privacy, dirty, overcrowded, and structured to control movement due to the security focus, which are all factors that can create barriers to family interactions, upset children, cause anxiety, grief, shame, and frustration, and negate any positive value resulting from a visit (Arditti 2003; Arditti 2005; Beckmeyer and Arditti 2014; Benning and Lahm 2016; Comfort 2003; Dixey and Roodall 2012; Hairston 1998; Hutton 2016; Pierce 2015; Tartaro and Levy 2017). Visits held in such conditions "suggest a lack of psychological safety and do not support an enduring bond among children, family members, and parents" (Arditti 2012, 194) with poor quality visits between incarcerated parents and their children resulting in higher reports of child trauma symptoms (Arditti and Savla 2015).

Glass partition visits between parents and their children can prevent the formation of family bonds and create emotional difficulties (Hairston 1998; Schubert, Duininck, and Shlafer 2016). Institutional policies can also limit physical contact and movement during visits, which can distance prisoners from their loved ones (Arditti 2012; Hutton 2016). For example, restrictions can prohibit intimacy (e.g., sitting next to one another) and limit a prisoner's ability to sit and play with their child (Hutton 2016). Most jurisdictions limit prisoners and their visitors to hugging and kissing at the start and end of the visit, which can be difficult for children in particular to understand (Arditti 2003; Hairston 1998; Schubert et al. 2016). Other institutional regulations that make in-person visitation difficult include physical searches of children and limiting visitation to certain days and times of the week (Phillips 2012; Sturges 2002). The strict application of prison regulations (e.g., regulations about what visitors can wear) and poor treatment from prison staff can lead to secondary prisonization (Comfort 2003; Hutton 2016). While participants in Arditti's (2003) study described harsh/disrespectful treatment from jail staff as a challenge to visitation, participants in Tewksbury and DeMichele's (2005) study reported positive perceptions of staff.

Christian (2005) described visitation as a collateral consequence of incarceration given that travelling to the institutions is costly, tiring, and time-consuming. In fact, the most cited disadvantages of in-person visitation for visitors are the distance and cost (e.g., gas, lodging, missed work; Arditti 2003; Arditti 2005; Christian 2005; Digard et al. 2016; Dixey and Roodall 2012; Mowen and Visher 2016; Pierce 2015; Schubert et al. 2016; Tartaro and Levy 2017; Tasca 2015; Tewksbury and DeMichele 2005). Family and friends can invest substantial time and resources to travel to an institution, and once there, can be subject to lengthy wait times and uncertainty about whether they will get a visit (Arditti 2003; Comfort 2003).

\section{$\underline{\text { Video Visitation }}$}

Video visitation is thought to ameliorate some of the disadvantages of in-person visitation. Prisoners at Brevard County Jail in Florida and their visitors were the first to participate in on-site video visitation (Tartaro and Levy 2017). Since the use of video visitation emerged in Florida in 1995, correctional administrators in several states (e.g., Alabama) and countries (e.g., Canada) have followed suit. Thirty percent of state departments of corrections were using video visitation as of late 2014 (Digard et al. 2016). It is most common in jails despite the reality it serves to benefit state and federal prisoners incarcerated far from their loved ones more (Rabuy and Wagner 2015).

There are variations in the use of video visitation that range from supplementing other forms of visitation to providing prisoners with video visitation due to a permanent prohibition from other forms of visitation (Boudin et al. 2014). Prisons are more likely to offer in-person, contact visitation and supplement with video visitation whereas jails are more likely to eliminate in-person, glass partition visits altogether once they implement video visitation (Rabuy and Wagner 2015; Tartaro and Levy 2017). Video visitation also varies in how it is offered. Regional video visitation typically involves visitors travelling to facilities that are more centrally located than the institutions where their loved ones are incarcerated to communicate via computer kiosks. On-site video visitation involves visitors travelling to correctional institutions to communicate via computer kiosks located in a non-secure portion of the facility. Lastly, and the focus of the current study, is remote video visitation whereby visitors can visit with their incarcerated loved 
This is an author-produced, peer-reviewed version of this article. The final, definitive version of this document can be found online at Journal of Crime \& Justice, published by Taylor and Francis. Copyright restrictions may apply. https://doi.org/10.1080/0735648X.2019.1653216. The content of this document may vary from the final published version.

ones using Internet access on smartphones, tablets, computers, and/or public kiosks. In some jurisdictions, prisoners are provided with access to tablets whereas in other jurisdictions, they are given access through computer kiosks located in communal living units or a separate visitation space in the institution (Loper and Coleman 2014).

There is minimal academic literature exploring the use of video visitation; much of the existing literature is anecdotal in nature and/or it has examined the practice in prison settings (see e.g., Digard et al. 2016). The exception is the study conducted by Tartaro and Levy (2017) who examined visitor preferences for visitation modality (in-person Plexiglas visits, on-site video visitation, and remote video visitation) in three county jails (two in New Jersey and one in Nevada). Visitors who participated in in-person Plexiglas visits reported their visits as being more stressful than those who participated in on-site or remote video visitation; reasons for this stress included long wait times, unsanitary conditions, and the lack of physical contact with their loved one. Those who participated in remote video visitation were the most likely to report that cost (i.e., access to a computer with a camera and the Internet) was an issue for the visit although remote video visitation was identified as the most convenient visitation modality.

Video visitation is said to be beneficial for prisoners, visitors, and correctional administrators. For example, prisoners and their visitors benefit from these systems because correctional services can increase the number and length of visitation hours (Brown, Cosby, and Buell 2014; Del Dago 2012; Digard et al. 2016; Dueker 2004; Fulcher 2014; Loper and Coleman 2014; Tartaro and Levy 2017) and increase the number of visitors prisoners can have (Grohs 2013). Video visitation might also increase access to visitation for people in circumstances where disability or age create barriers to visitation (Boudin et al. 2014).

Other benefits include reducing: visitors' travel time (Boudin et al. 2014; Johnson and Hesse 2005; Loper and Coleman 2014), and thus, visitors' travel and lodging costs (Boudin et al. 2014); wait times for visits (Grohs 2013; Johnson and Hesse 2005); the likelihood visitors will be turned away from visits due to long line-ups (Del Dago 2012); and, the length of time it takes for individuals to receive security clearance (Brown et al. 2014). The use of video visitation also eliminates the necessity of corrections staff patting-down and searching visitors (Del Dago 2012; Grohs 2013; Phillips 2012). Prisoners and their children benefit from video visitation that allows them to play games with one another during video visits, and child visitors might benefit from being able to visit from the comfort of their home (Phillips 2012).

Corrections administrators are said to benefit from video visitation because it increases institutional security and order (e.g., by reducing opportunities for contraband to enter facilities [Boudin et al. 2014; Brown et al. 2014; Del Dago 2012; Grohs 2013; Johnson and Hesse 2005; Phillips 2012; Rogers 2013]), promotes staff and prisoner safety (Dueker 2004; Rogers 2013), and makes it easier for correctional administrators to record and monitor visits (Loper and Coleman 2014). However, the Texas Criminal Justice Coalition's (2014) examination of Travis County's switch to video-only visitation found that disciplinary infractions and incidents, prisoner-on-prisoner and prisoner-on-staff assaults, and contraband infractions increased in the year following the replacement of in-person visitation with video visitation.

Video visitation is argued to reduce the time and costs associated with processing visitors, supervising visits, and moving prisoners throughout the institution (Brown et al. 2014; Del Dago 2012; Dueker 2004; Grohs 2013; Loper and Coleman 2014; Rabuy and Wagner 2015), so staff are believed to have more time to engage with prisoners (Johnson and Hesse 2005). There are also reported cost savings in the construction of new facilities (Del Dago 2012; Grohs 2013); Dueker (2004) estimated new construction cost savings of 50 percent or more. Video visitation can also create the opportunity for correctional agencies to generate revenue by charging a fee to utilize the system (Grohs 2013; Fulcher 2014; Phillips 2012; Tartaro and Levy 2017). Although only five of the 15 states that reported to the Vera Institute that they offered video visitation and charged a fee for its use reported that they generated revenue (Digard et al. 2016). All but one of those five agencies put the revenue that was generated into programming for their incarcerated population.

The disadvantages of video visitation impact primarily prisoners and their visitors rather than correctional administrators. A potential disadvantage is that prisoners and/or their families may be responsible for paying for visits. Costs of video visits vary depending on the service provider. Rabuy and Wagner (2015) reported that in 2014, Telmate charged anywhere from 33 to 66 cents per minute and Securus charged anywhere from 50 cents to $\$ 1.50$ per minute. Nearly half of the prisoners surveyed by Digard et al. (2016) reported that the cost of the service $-\$ 12.95$ for a 30 minute visit - meant they did not use the service at all, or that it prevented them from using it more. The cost of purchasing or owning the technology and Internet services required to use video visitation may also preclude certain 
This is an author-produced, peer-reviewed version of this article. The final, definitive version of this document can be found online at Journal of Crime \& Justice, published by Taylor and Francis. Copyright restrictions may apply. https://doi.org/10.1080/0735648X.2019.1653216. The content of this document may vary from the final published version.

prisoners and their visitors from using video visits (Loper and Coleman 2014). One-fifth of Digard et al.'s (2016) respondents reported not using video visitation because their loved ones did not have Internet access and respondents in Tartaro and Levy's (2017) study who had used remote video visitation were most likely to cite cost as a significant challenge.

Another criticism of video visitation relates to the technical difficulties experienced when using these systems, such as difficulties scheduling visits (Rabuy and Wagner 2015). Participants in Sturges and Al-Khattar's (2009) study expressed a desire for contact visits due to their dissatisfaction with video visitation at one of the jails under study. The image quality was poor and they experienced difficulties maintaining eye contact. Seventy percent of the prisoners surveyed by Digard et al. (2016) disagreed or somewhat disagreed that they were "satisfied with the sound quality of [their] video visits" (18), reporting delays in sound and a disconnect between sound and picture. Video visits can make it difficult for families to view the prisoner due to the quality of the image and their inability to assess the prisoner's overall physical well-being from head to toe (Rabuy and Wagner 2015). There is often limited privacy due to where visitation kiosks are located (e.g., in common areas of housing units; Rabuy and Wagner 2015).

An additional concern with the implementation of video visitation is whether the corrections agency eliminates inperson visits rather than providing the service to supplement them. Rabuy and Wagner (2015) reported that 74 percent of county jails banned in-person visitation services once their facilities were equipped for video visitation, which forced these services on their clients and visitors. It is also possible that the regional visitation facilities or remote locations (e.g., those in churches and bail bond companies) may require visitors to invest in significant travel, gas, and lodging costs (Loper and Coleman 2014).

One of the disadvantages that correctional administrators have expressed concern about is the potential for prisoners and their visitors to abuse the practice, such as when visitors are not vetted properly by correctional services for security risks, or when measures are not in place to enforce no-contact orders (Rogers 2013). Findings from one study suggest this fear is not founded; a WADOC employee reviewed the first 500 video visits conducted by prisoners in their system and found that fewer than 3 percent of the visits were deemed to include inappropriate behavior (Digard et al. 2016).

While video visitation has the potential to offer a number of advantages, there are important disadvantages to consider as well, and further research is needed to more closely examine these. This study contributes to the scant body of academic literature examining video visitation, and it does so through the lens of jail prisoners, an understudied population that is directly impacted by its use.

\section{The Present Study}

The current study examines a remote video visitation system - one of the first systems of its kind in North America that was implemented by a Sheriff's office in the Northwestern United States in 2010. Initially, the Sheriff at the time collaborated with a local technology company to develop their own Internet-based remote video visitation system. In late 2013, the agency started using Telmate's video visitation system and continues to do so to date. At the time of data collection, the prisoners used kiosks located in common areas to complete their two free weekly 30-minute video visits and purchased additional visits at a cost of $\$ 9$ for 30 -minutes.

\section{Methodology}

To examine prisoners' perceptions about the remote video visitation system, data were collected via interviews with a purposive sample of prisoners who were experienced users of the system and paper surveys of prisoners from a random selection of jail housing units. Institutional Review Board approval was requested and granted.

A sergeant with the jail identified prisoners who were experienced users of the video visitation system and provided them with copies of the interview recruitment/cover letter and informed consent document. The prisoners were instructed to notify a deputy on their living unit if they were interested in participating in the study. The interviewer used a semi-structured interview schedule to ask the participants eight open-ended questions to capture their personal experiences with video visitation. The face-to-face interviews lasted between 10 and 40 minutes. Questions examined how frequently they use the system, who pays for their additional video visits, their preference for in-person versus video visits, their perceptions of the advantages and disadvantages of the system, how their use of the system affects 
This is an author-produced, peer-reviewed version of this article. The final, definitive version of this document can be found online at Journal of Crime \& Justice, published by Taylor and Francis. Copyright restrictions may apply. https://doi.org/10.1080/0735648X.2019.1653216. The content of this document may vary from the final published version.

their ability to maintain contact with family and friends, and whether they believe maintaining contact with their loved ones will contribute to their success upon release. Eleven of the 12 interviews were tape recorded and later transcribed for analysis (one prisoner declined to be tape recorded so the interviewer took extensive notes).

Paper surveys were administered to gather additional data from a larger sample of prisoners. To select the sample for the survey, a stratified sample of jail housing units was gathered. Three of the housing units were excluded from the sampling frame because they housed infirm or mentally ill prisoners who would not have been able to complete the survey. The remaining 10 units comprised the sampling frame. To ensure the final sample included males and females, the sampling frame was stratified by sex and random samples were drawn from each. All 259 prisoners housed in the selected units (one female unit, two male units) were invited to complete the survey. In order to encourage participation and honest responses, respondents were assured anonymity.

The 30-item survey included questions to ascertain prisoners' experiences with, and perceptions about, video visitation, many of which mirrored the questions asked in the interviews. The first section assessed participants' use of video visitation including when they last used it, how often they use it in an average week, how long most visitations last, whether they purchase additional visits, and with whom they visit. Each item was followed by a list of appropriate response choices. The next section of the survey included 10 Likert scale agreement/disagreement items to assess opinions about video visitation including its effect on staying in touch with family, institutional behavior, and recidivism (e.g., "The video visitation program helps me to stay in touch with my family", "The fact that video visitation privileges can be taken away has made me behave better in the jail"). Opinions about the ease of use of the system and preferred mode of visitation were also measured (e.g., "It is pretty easy to use the video visitation program", "I prefer video visitation over in-person visitation"). These 10 items were combined to create an index with scores ranging from 10 to 50; higher scores indicated more positive opinions about video visitation. Last, participants were asked basic demographic questions.

Consistent with general survey research recommendations (Dillman, Smyth and Christian 2009), and accounting for that fact that incarcerated populations can include individuals from a wide range of education levels, the survey items were brief and utilized language appropriate for an approximate eighth grade reading level. In addition, as is discussed in more detail below, the majority of the sample reported completing at least their high school diploma. However, it is possible that some prisoners were not able to participate in the survey due to literacy challenges.

Survey packets, containing a cover letter, informed consent document, and the survey, were delivered to the jail. Prisoners in the three selected housing units were invited to participate by a deputy. Those who consented were asked to complete the survey and return it to the deputy in a blank envelope. Implicit consent for participation, rather than a signed informed consent document, was utilized to maintain anonymity. Once the envelope was checked for contraband, it was sealed and set aside for the researchers to retrieve. The only information tracked was the housing unit of the prisoner who completed the survey.

\section{Results}

The interview data were first transcribed and then analyzed in NVivolO. Analyses of the interview data began with open coding rather than the use of a predetermined coding scheme to determine what could be inferred from the data. Open coding was used to identify common experiences and perceptions regarding the use of video visitation. The 26 open codes were conceptualized during axial coding, and lastly, during selective coding, five key themes emerged from the data, all of which are presented in the results. Survey data were analyzed in Statistical Package for the Social Sciences software, focusing primarily on descriptive statistics. The results are organized by themes and discussed together below, noting important similarities and differences between the data collected from the two procedures.

\section{Sample Characteristics}

Sixteen prisoners voiced interest in participating in an interview although only 12 were ultimately interviewed. Two were released the day of the interviews, one declined to participate, and the decision was made not to interview a prisoner who was experiencing significant mental distress. Given the manner in which respondents were invited to participate (i.e., identified by a sergeant as experienced users of video visitation), it is not possible to calculate the participation rate. However, the goal of the interviews was to gather rich, qualitative data from a purposive sample of 
This is an author-produced, peer-reviewed version of this article. The final, definitive version of this document can be found online at Journal of Crime \& Justice, published by Taylor and Francis. Copyright restrictions may apply. https://doi.org/10.1080/0735648X.2019.1653216. The content of this document may vary from the final published version.

prisoners who had used the system multiple times. Of the 12 prisoners who were interviewed, 10 were male and two were female. To protect confidentiality, male pseudonyms are used for all interview participants and additional demographic data were not collected from the interview sample.

For the survey, all of the prisoners in the selected housing units were invited to participate ( $N=259)$. Sixty surveys were returned, two of which were entirely blank, resulting in a final sample size of 58 and an approximate $23 \%$ response rate. Although the response rate was low, research indicates that a low response rate is not necessarily indicative of non-response error and that response rates as low as $10 \%$ can yield valid estimates (Wright 2015). In addition, the survey sample was comparable to the overall jail population in regard to educational attainment and age. Almost three-quarters of the sample had earned a high school diploma/GED or higher (see Table 1) which is similar to the jail's population in which about $78 \%$ have a high school diploma/GED or higher. The sample ranged in age from 19-58 years with an average of 32 years, which is consistent with the population's average age at booking of 33 years old. However, contrary to the interview participants who were primarily male (83.3\%), the survey sample was disproportionately female $(62.1 \%)$. While this is not representative of the jail population in which about $22 \%$ are female, it is common in survey research for samples to be overrepresented by females (Dillman et al. 2009).

\section{Table 1: Survey Sample Characteristics $(\mathrm{N}=58)$}

\begin{tabular}{lll}
\hline Variable & Attributes & Descriptives \\
\hline Sex & Male & $22(37.9 \%)$ \\
& Female & $36(62.1 \%)$ \\
Education Level & Less than high school diploma/GED & $15(25.8 \%)$ \\
& High school diploma/GED & $21(36.2 \%)$ \\
& Some college & $14(24.1 \%)$ \\
& College degree & $7(12.1 \%)$ \\
Age & Other & $1(1.7 \%)$ \\
& Age in years & Mean $=32.31$ \\
& & SD $=9.94$ \\
\hline
\end{tabular}

\section{Use and Perceptions of Video Visitation}

The interview and survey participants indicated regular use of video visitation. All of the interview participants were experienced users and almost three-quarters $(n=44 ; 74.1 \%)$ of the survey respondents had used it before. Survey participants who indicated they had not used the system $(n=14 ; 25.9 \%)$ were directed to the end of the survey since the remaining items would not apply to them. Instead, they were asked why they had not used the system. Responses included: the difficulty of scheduling visits $(n=6)$, the hours it can be used do not work for them $(n=5)$, they do not know anything about it $(n=2)$, and there is no one to visit with $(n=1)$.

Eleven of the 12 interview participants said they schedule two video visits every week and the average weekly number of visits indicated by survey respondents who use the system was $1.89(\mathrm{SD}=0.89)$. Most indicated satisfaction with this format though some would prefer longer visits, while others prefer shorter, more frequent visits. Interview and survey respondents indicated they visit with a variety of people including their parents, children, intimate partners, other relatives, and friends.

In addition to the two free, 30-minute video visits prisoners are provided each week, they are able to purchase additional video visits at a cost of $\$ 9.00$ for 30 minutes. While $83.3 \%$ of survey respondents were aware their ability to do this, almost $80 \%$ indicated they had never done so. Ninety percent identified the cost as the main factor preventing them from purchasing additional visitation time. Eight of the interview participants expressed similar concerns. Andrew, who said he does not use additional video visits, explained:

I tell my [wife], don't send me money, I'm fine, it's just a couple of weeks ... I'd prefer to have more visits and the cost, I mean $\$ 9$ for 30 minutes is kind of high. You know? I mean, $\$ 20$, nearly $\$ 20$ for an hour, you know? But, I guess it makes sense in a way with the free visits and then the, the fee on top for extra visits. I don't know. 
This is an author-produced, peer-reviewed version of this article. The final, definitive version of this document can be found online at Journal of Crime \& Justice, published by Taylor and Francis. Copyright restrictions may apply. https://doi.org/10.1080/0735648X.2019.1653216. The content of this document may vary from the final published version.

This quote shared by Andrew - who is a parent - captures the reality that paying for additional visits may not be an option for some prisoners and their families.

As described above, the survey included a 10-item Likert scale to measure perceptions about video visitation in which higher scores indicated more positive opinions. Reliability analysis suggested that the scale was internally consistent $(\alpha=.800)$. While possible scale scores ranged from 10 to 50, scale scores among the sample ranged from 10 to 44 with an average of 26.15 ( $\mathrm{SD}=7.230$ ). Assuming a mid-point of 30 (i.e., answering Neutral to every item), the sample mean was significantly lower $(t(40)=-3.413, p=.001)$, suggesting somewhat negative perceptions. Each scale item is displayed below in Table 2 with collapsed response categories.

Table 2: Opinions about IVV: Survey Scale Items (N=44)

\begin{tabular}{|c|c|c|c|}
\hline Item & Agree & Neutral & Disagree \\
\hline The video visitation program is very helpful for inmates. & $15(35.7 \%)$ & $18(42.9 \%)$ & $9(21.4 \%)$ \\
\hline It is pretty easy to use the video visitation program. & $20(47.7 \%)$ & $14(33.3 \%)$ & $8(19.0 \%)$ \\
\hline $\begin{array}{l}\text { The hours when video visitations are allowed work for me } \\
\text { and the people I visit with. }\end{array}$ & $21(48.8 \%)$ & $8(18.6 \%)$ & $14(32.6 \%)$ \\
\hline $\begin{array}{l}\text { I think there are some problems with the video visitation } \\
\text { program. }\end{array}$ & $35(81.4 \%)$ & $5(11.6 \%)$ & $3(7.0 \%)$ \\
\hline $\begin{array}{l}\text { The video visitation program helps me stay in touch with } \\
\text { my family. }\end{array}$ & $26(61.9 \%)$ & $6(14.3 \%)$ & $10(23.8 \%)$ \\
\hline $\begin{array}{l}\text { Being able to have video visitations with my friends and } \\
\text { family has made me want to improve my behavior when I } \\
\text { am released from jail. }\end{array}$ & $16(37.2 \%)$ & $15(34.9 \%)$ & $12(27.9 \%)$ \\
\hline $\begin{array}{l}\text { The fact that video visitation privileges can be taken away } \\
\text { has made me behave better in the jail. }\end{array}$ & $12(27.3 \%)$ & $15(34.1 \%)$ & $17(38.6 \%)$ \\
\hline $\begin{array}{l}\text { I think the video visitation program will help to stop me } \\
\text { from committing another crime when I am released from } \\
\text { jail. }\end{array}$ & $5(11.6 \%)$ & $14(32.6 \%)$ & $24(55.8 \%)$ \\
\hline I prefer video visitation over in-person visitation. & $3(6.8 \%)$ & $4(9.1 \%)$ & $37(84.1 \%)$ \\
\hline $\begin{array}{l}\text { I think in-person visits would help me to stay in touch with } \\
\text { my family better than video visitations. }\end{array}$ & $37(86.0 \%)$ & $3(7.0 \%)$ & $3(7.0 \%)$ \\
\hline
\end{tabular}

In terms of overall opinions about video visitation, only about one-third (35.7\%) of survey respondents who have used the system agreed that it is "very helpful for inmates" and the majority (81.4\%) agreed that there are some problems with it (see Table 2). In contrast, the interview participants revealed a greater degree of overall satisfaction with the system. For example, Raymond expressed how the system is helping him maintain contact with his young son: "He seen me this last video visit and he got all excited, which made me kind-hearted; yeah, it made me really appreciate the video visits that they give us to use for free." Similarly, Michael discussed how video visitation is a privilege, recognizing that prisoners at the jail "are getting privileges that a lot of people don't even have on the out."

In terms of scheduling, about half (48.8\%) of survey respondents agreed that the hours when video visitation is available work for them and their visitors. Ten of the interview participants expressed appreciation for the scheduling convenience of video visitation. For instance, Morgan explained: "The advantage is that you get to pick when, you 
This is an author-produced, peer-reviewed version of this article. The final, definitive version of this document can be found online at Journal of Crime \& Justice, published by Taylor and Francis. Copyright restrictions may apply. https://doi.org/10.1080/0735648X.2019.1653216. The content of this document may vary from the final published version.

know what I mean? So you can like schedule what works with them, that's probably the good thing, and they get to be in their comfort zone." Three of these prisoners also spoke specifically about the convenience for out-of-state family and friends.

Although opinions about scheduling were generally positive, there were concerns about ease of use. While just under half (47.7\%) of survey respondents agreed that the system is "pretty easy to use" (see Table 2), the comments section at the end of the survey described technological difficulties with the system including dropped calls and poor video quality. Eight of the interview participants also discussed experiencing technological issues. For example, Morgan and Scott described poor video quality and auditory issues with the system:

Just to be able to see her is good but, I don't know, it, it just sucks sometimes cause like no matter how good their camera is, the pixilation is still really, you know what I mean? Like she went and bought like a $\$ 150$ little set-up thing and she's all excited about it but then it was still pixelling and she took it back and got like a $\$ 20$ one and it was the same. (Morgan)

The only thing with the, with the system, like, if I'm talking, I can't hear what they're saying and vice versa, and it's kind of delayed, so if you're talking, you kind of have to wait for them to finish and then talk, otherwise it kind of cuts them off, so that and the pixilation. (Scott)

Survey respondents were generally positive about the ability of video visitation to help them maintain relationships as $61.9 \%$ agreed that the system helps them to stay in touch with their friends and family (see Table 2). All 12 of the interviewees were similarly positive, identifying maintaining contact with their loved ones as a major advantage of video visitation. For example, Timothy shared these sentiments about visitation:

You know no matter what, you know where everybody puts on a front on or whatever, but again, to talk to your family, you know that's, that's always a big step, in help, you know, and getting some kind of outside civilization, them letting us know that we're humans too and that's always a plus, not feeling like a caged animal all the time.

Michael also talked about the importance of the visits in terms of maintaining ties with his loved ones and keeping him focused on his future:

The visits made the time here go by a lot quicker. Just being able to keep in touch and being able to see their faces on a weekly basis I think it's just, it's helped so much because I know what I have to look forward to when I get out, I know that they're waiting for me.

Ten of the interview participants said that access to video visitation contributes to their desire to abide by the rules in the jail because they value their visits, which can be taken away for poor behavior. Andrew described how the threat of losing visitation privileges is a strong incentive to behave:

I've seen a lot of people who try to stay straight so that they don't lose those visits because that's all they have. A lot of them can't even use the phone system because of the money situation or whatever it is, so they, you know, they try to do great.

In addition, five of the interview participants described how video visitation may ease their reintegration into society, due primarily to their ability to maintain ties with their loved ones while incarcerated. For instance, Raymond had a huge smile on his face as he described how video visitation has allowed his family members to see him sober, which will motivate him to maintain his sobriety once he is released:

It's helping me out because of the fact that my ex and my son get to see me sober, my Dad gets to see me sober, that's all they wanted and they get to see it before I get out and I seen how happy it made them to see me sober, so I'm going to continue it when I get out.

In contrast, when asked if the threat of losing video visitation privileges has improved their behavior, only about $28 \%$ of survey respondents agreed (see Table 2). Additionally, only $37.2 \%$ agreed that video visitation has made them want to improve their behavior upon release. When asked if it would help to reduce their chances of offending, only five prisoners (11.6\%) agreed and over half of the sample (55.8\%) disagreed. 
This is an author-produced, peer-reviewed version of this article. The final, definitive version of this document can be found online at Journal of Crime \& Justice, published by Taylor and Francis. Copyright restrictions may apply. https://doi.org/10.1080/0735648X.2019.1653216. The content of this document may vary from the final published version.

The majority of survey participants indicated a clear preference for in-person visits over video visits. In fact, $84.1 \%$ indicated they prefer in-person visits and $86.0 \%$ agreed that in-person visits would help them to stay in touch with their family better (see Table 2). In addition, the qualitative comments left at the end of the survey described a desire to have in-person visits instead, or at least the option to choose as many visitors do not have access to the technology required for video visits. Since the jail no longer allows in-person visits aside from attorneys and other professional staff, some prisoners are not able to visit with any of their loved ones during their incarceration.

Five of the interviewees expressed their preference for in-person visits as well. For example, Morgan explained how he prefers in-person, glass partition visits because they are more personal and intimate:

I say glass visits just because like you see the person real, like, you really see 'em. And the other way, I mean, it's more convenient the other one, to be on a screen but you know, at home, doing whatever, but, it's just like, more personal than like, I mean, you can't touch them but you can still see-see them, you know what I mean? (Morgan)

Three of the interview participants also suggested having the choice between in-person or video visits. For instance, Zachary expressed a preference for in-person, glass partition visits but explained how his circumstances - being incarcerated in a different state than where his family resides - influences his current preference for video visitation:

I prefer the glass, in-person visits but like to have the video visits available so I can visit with family in California because my family lives there. I'd prefer the glass if my family was local, so I could see my family.

Five of the interview participants described how they prefer video visits when visiting with their children. For example, Samuel talked about how his kids had visited him in jail on previous occasions and how he "just thought it was, gross. Kind of, I mean. I felt bad you know? My kids had to hold their hands up and get wands over them and things." Timothy discussed how video visits are easier than phone calls because with a telephone call, "her [his four year old daughter's] attention span goes right away [but when] she sees me, she'll stay right there and talk to me." Michael explained how much he thinks he and his family benefit from the video visits:

My wife literally moved out the couch and they showed me this new dance they're doing and I thought that was really cute, and I just think it's a lot, like I got to see my Mom yesterday - she went to the house, it's just, it's better, it is better in that perspective because you get to visit with whomever goes, you know what I mean? Like you don't have a limit, like, 'Oh, you can't visit.' So I think that's pretty cool too and I wasn't expecting my Mom to be there, so it was really nice.

The ability to avoid entering the jail environment appears to be a clear advantage of video visitation over in-person visitation, particularly for parents. However, the issues highlighted by the survey respondents point to an important disadvantage: not everyone has access to the resources required for video visits. Considering some of the other disadvantages of video visitation gleaned from this study, such as technological issues and a less intimate visitation experience, the preference for the choice between video or in-person visits is not surprising.

\section{Discussion}

The goal of this study was to add to the limited body of research on video visitation and visitation practices in jail, and from the perspective of incarcerated individuals themselves. To that end, interviews and surveys were conducted with prisoners from a county jail in the Northwestern US that had replaced in-person visitation with remote video visitation in 2010. The results suggest mixed perceptions about the video visitation system, though there were a number of similar experiences and opinions expressed by the survey and interview respondents.

Both groups indicated relatively regular use of video visitation (i.e., two visits per week) with a variety of family and friends, which helps them to maintain relationships while incarcerated. Negative opinions expressed by both groups included the prohibitive cost of purchasing additional visits and technical difficulties with the system, which is consistent with existing literature describing issues in regard to access to, and the quality of, video visits (Digard et al 2016; Loper and Coleman 2014; Raby and Wagner 2015; Sturges and Al-Khattar 2009; Tartaro and Levy 2017). In addition, more than $80 \%$ of the survey respondents and eight of the 12 interview respondents indicated either a preference for in-person visits or the option to choose between in-person and video visits. 
This is an author-produced, peer-reviewed version of this article. The final, definitive version of this document can be found online at Journal of Crime \& Justice, published by Taylor and Francis. Copyright restrictions may apply. https://doi.org/10.1080/0735648X.2019.1653216. The content of this document may vary from the final published version.

In terms of differences, interview respondents were markedly more positive about video visitation than survey participants. All of the interview participants expressed satisfaction with, and appreciation for, video visitation. Additionally, whereas most $(\mathrm{n}=10)$ believed video visitation had a positive impact on their behavior in the institution, as well as upon release, survey respondents were doubtful about it having any effect on their behavior. Last, while survey respondents clearly favored in-person visitation, interview participants with young children and family who live out of state were appreciative of video visitation, as their children are not exposed to the institutional environment and out-of-state visitors are not required to make lengthy trips to visit (a common criticism of in-person visitation, see Christian 2005).

The differences between the interview and survey respondents were quite striking and could be due to methodological factors. In an effort to recruit prisoners who were frequent users of the system, purposive sampling was used to gather the interview sample while random sampling was used for the survey to obtain a wider range of experiences and opinions. In addition, the survey was anonymous which allowed respondents to feel more comfortable being honest about their perceptions whereas social desirability could have been a factor in the interviews. The differences could also be a function of self-selection in that prisoners who held positive perceptions about video visitation were more likely to agree to participate in an interview. Last, the majority of the survey items were closed-ended with predetermined response choices while the interview questions were open-ended, which allowed for dialogue and a more in-depth exploration of perceptions.

In addition to methodological explanations for the differences between interview and survey participants, it is also possible that gender could explain the disparities given that the interview sample was primarily male and the survey sample primarily female. Research suggests that incarcerated women are more likely than their male counterparts to have experienced physical or sexual abuse in their lifetime, suffer from substance abuse or mental health issues, and be the primary caretaker of a child (Bloom, Owen and Covington 2013; Praetorius, Terry and Burse 2017). Consequently, adapting to a jail environment may be particularly difficult for females which could partially explain the more negative perceptions displayed by the disproportionately female survey respondents.

Overall, the current study indicates there is the potential for video visitation to produce positive outcomes similar to those resulting from in-person visitation; for example, by facilitating the maintenance of family ties, which can assist prisoners upon their release (Liu, Pickett, and Baker 2014; Mowen and Visher 2016). In addition, video visitation can address some of the disadvantages of in-person visitation, including limited visitation hours, the security screening process, and the time and effort required to get to an institution to sometimes experience lengthy wait times before a visit (Arditti 2003; Comfort 2003; Phillips 2012; Sturges 2002). However, the findings also point to a number of disadvantages of video visitation including technological issues such as dropped calls, a less personal visitation experience, and access to the technology required for friends and family to visit with their incarcerated loved one.

The findings of this study point to a number of policy and practice recommendations. First, correctional services should offer video visitation as a supplement to, rather than a replacement of, in-person visits. Choice is necessary when one considers the barriers that exist for visitors wanting to see their loved ones, including a lack of access to the Internet and/or the technology required to use remote video visitation. Second, correctional agencies should install kiosks for visitor use in their lobbies, and/or pursue partnerships with community agencies to provide kiosks, free Wi$\mathrm{Fi}$, and private visitation space in various community locations to ensure that visitors who do not have the means to use video visitation can still visit their incarcerated loved ones. Third, correctional agencies should not create policies that require prisoners and their visitors to pay a fee as such costs can be prohibitive. Fourth, correctional services that limit the number of visits prisoners can receive per week should award extra free visits for good institutional conduct. Such a policy would allow prisoners to maintain relationships that might have a positive effect on their institutional behavior and future recidivism while also promoting institutional security and order. Last, correctional agencies should engage in continuous dialogue with their clients and their visitors, staff, and service providers to ensure the highest standard of quality of video visitation is being provided. Arguably, this feedback mechanism is crucial in jurisdictions where video visitation has been implemented to replace in-person visitation, and where costs are incurred to utilize the service.

\section{Limitations and Future Research}

While this study makes a valuable contribution to the limited literature examining video visitation in correctional settings, and visitation in jail environments, it is important to recognize some of the limitations. First, the response rate for the survey was low and nonprobability sampling and a small sample comprised of primarily men limit the 
This is an author-produced, peer-reviewed version of this article. The final, definitive version of this document can be found online at Journal of Crime \& Justice, published by Taylor and Francis. Copyright restrictions may apply. https://doi.org/10.1080/0735648X.2019.1653216. The content of this document may vary from the final published version.

representativeness and generalizability of the interview data. It is likely the response rate is low due to having Sheriff's deputies provide prisoners with recruitment materials for the study because some prisoners may have declined participation to avoid being perceived as acting in line with the institution. It is also possible that literacy challenges prevented some prisoners from participating in the survey. While it is important to acknowledge the above limitations, and the fact that those who did not participate might have shared different perspectives, these limitations do not negate the contribution this exploratory research about video visitation in a jail setting makes to the limited body of research in this area.

This study was conducted in one jail in the Northwestern US and involved the examination of a remote video visitation system, so caution should be taken in generalizing the findings to other types of correctional populations, other localities, and to other video visitation modalities. Since the average length of stay at a jail is short, it is important to examine the impact of video visitation in various prison settings where average stays are much longer. In combination with the type of video visitation, the rurality or urbanity of a location could have a significant effect on the use and benefits of video visitation. For example, an on-site video visitation in a rural area may result in considerable travel difficulties for visitors.

Remote video visitation systems allow visitors to virtually visit with their incarcerated loved ones from any location. In contrast, regional and on-site programs require visitors to travel to a regional center or to the correctional institution for video visits. As such, future research should examine the differential use, effects of, and the challenges inherent in using various types of video visitation. To illustrate, remote video visitation requires visitors acquire access to the requisite equipment and Internet services, which can be quite costly. Visitors using on-site video visitation do not incur these costs; however, they might incur transportation and lodging costs to travel to correctional facilities for onsite visits, which is a cost remote video visitation users do not experience.

Future research should also employ the use of quasi experimental designs to enhance internal validity; for example, at correctional facilities considering the implementation of a video visitation system, a quasi experimental design would allow for an examination of important outcome variables such as institutional behavior, recidivism, security, and users' opinions about visitation before and after implementation. Additionally, opinions about the use of the system, from both prisoners' and visitors' perspectives, could also be gathered using anonymous surveys, and possibly, part or all of the survey used in this study. Last, given the differing opinions identified between interview and survey participants, future research on video visitation should more closely examine differences based on prisoner gender and parental status.

The current study found mixed results regarding the effect of video visitation on prisoners' institutional behaviour, which mirrors the literature on in-person visitation. These findings suggest that similar to future research investigating the effect of in-person visitation on prisoners' institutional and community behavior, research examining video visitation should also examine this topic through the lens of social support theory to assess "how visitation matters" (Meyers et al 2017, 58). The findings that emerged from both forms of data highlight the need to examine whether video visitation has the potential to "reset" family relations (Tasca, Mulvey and Rodriguez 2016, 473) given that participants spoke highly about how video visitation helps them maintain relationships and further, five of the interview participants spoke directly of their preference to visit with their children using the video visitation system. With respect to the latter, future research should examine whether video visitation provides psychological safety for children and supports the bond amongst family members (Arditti 2012,194) while reducing child trauma symptoms (Arditti and Savla 2015).

This study makes an invaluable contribution to the existing literature examining video visitation and it does so from the perspective of individuals incarcerated in jail, a population whose voice has typically been excluded in previous studies, and who are amongst those most affected by the use of video visitation given that it is more common in jails and jail administrators are more likely to eliminate in-person visitation once they implement video visitation (Rabuy and Wagner 2015; Tartaro and Levy 2017). The insights shared by the prisoners in this study suggest that while the use of video visitation is not inherently problematic, correctional administrators must carefully consider a variety of factors to promote visitation for their clients (e.g., extra, free visits to incentivize good institutional behavior) and to ensure inclusivity in its use as it can be prohibitive due to costs and technology illiteracy. The key policy and practice recommendation is the need for correctional services to offer video visitation as a supplement to, rather than replacement of, in-person visitation. The current study also identifies the need for additional research to examine further the needs of incarcerated individuals and their visitors, and the effect of various forms of video visitation on family relations and incarcerated individuals' behaviour while incarcerated and upon their release into the community. 


\section{References}

Agnew, R. 1992. "Foundation for a General Strain Theory of Crime and Delinquency." Criminology 30 (1): 47-88. doi:10.1111/j.1745-9125.1992.tb01093.x.

Arditti, J. A. 2003. "Locked Doors and Glass Walls: Family Visiting at a Local Jail.” Journal of Loss and Trauma 8 (2): 115-138. doi:10.1080/15325020305864.

Arditti, J. A. 2005. "Families and Incarceration: An Ecological Approach." Families in Society: The Journal of Contemporary Social Services 86 (2): 251-260. doi:10.1606/1044-3894.2460.

Arditti, J. A. 2012. "Child trauma within the context of parental incarceration: A family process perspective."Journal of Family Theory and Review 4 (3): 181-219. doi:10.1111/j.1756-2589.2012.00128.x.

Arditti, J. A. and Savla, J. 2015. "Parental incarceration and child trauma symptoms in single caregiver homes." Journal of Children and Family Studies 24 (3): 551-561. doi:10.1007/s10826-013-9867-2.

Bales, W. D. and Mears, D. P. 2008. "Inmate Social Ties and the Transition to Society: Does Visitation Reduce Recidivism?" Journal of Research in Crime and Delinquency 45 (3): 287-321. doi:10.1177/0022427808317574.

Beckmeyer, J. J. and Arditti, J. A. 2014. "Implications of In-Person Visits for Incarcerated Parents' Family Relationships and Parenting Experience." Journal of Offender Rehabilitation 53 (2): 129-151. doi:10.1080/10509674.2013.868390.

Benning, C. A. and Lahm, K. F. 2016. "Effects of Parent-Child Relationships on Inmate Behavior: A Comparison of Male and Female Inmates." International Journal of Offender Therapy and Comparative Criminology 60 (2): 189-207. doi:10.1177/0306624X14551402.

Bloom, B., Owen, B., and Covington, S. 2003. "Gender Responsive Strategies: Research, Practice, and Guiding Principles for Women Offenders." National Institute of Corrections. June. Retrieved from https://s3.amazonaws.com/static.nicic.gov/Library/018017.pdf

Boudin, C., Stutz, T., and Littman, A. 2014. "Prison Visitation Policies: A Fifty-State Survey." Yale Law and Policy Review 32 (1): 149-189.

Brown, R. M., Cosby, J., and Buell, M. 2014. "Video Visitation in Corrections: Benefits, Limitations, and Implementation Considerations." National Institute of Corrections. December. Retrieved from https://nicic.gov/video-visiting-corrections-benefits-limitations-and-implementation-considerations

Brunton-Smith, I. and McCarthy, D. J. 2017. "The Effects of Prisoner Attachment to Family on Re-entry Outcomes: A Longitudinal Assessment." British Journal of Criminology 57 (2): 463-482. doi:10.1093/bjc/azv129.

Casey-Acevedo, K. and Bakken, T. 2002. "Effects of Visitation on Women in Prison: Who Visits and Who Cares?" Journal of Offender Rehabilitation 34 (3): 67-83. doi:10.1300/J076v34n03_05.

Christian, J. 2005. "Riding the Bus: Barriers to Prison Visitation and Family Management Strategies." Journal of Contemporary Criminal Justice 21 (1): 31-48. doi:10.1177/1043986204271618

Cochran, J. C. 2012. "The Ties that Bind or the Ties that Break: Examining the Relationship between Visitation and Prisoner Misconduct.” Journal of Criminal Justice 40 (5): 433-440. doi:10.1016/j.jcrimjus.2012.06.001.

Cochran, J. C. 2014. "Breaches in the Wall: Imprisonment, Social Support, and Recidivism." Journal of Research in Crime and Delinquency 51 (2): 200-229. doi:10.1177/0022427813497963.

Cochran, J. C. and Mears, D. P. 2013. "Social Isolation and Inmate Behavior: A Conceptual Framework for Theorizing Prison Visitation and Guiding and Assessing Research.” Journal of Criminal Justice 41 (1): 252-261. doi:10.1016/j.jcrimjus.2013.05.001.

Comfort, M. L. 2003. "In the Tube at San Quentin: The 'Secondary Prisonization' of Women Visiting Inmates." Journal of Contemporary Ethnography 32 (1): 77-107. doi:10.1177/0891241602238939.

Del Dago, F. 2012. "Solutions for Jail Visitations." American Jails 26 (1): 15-17.

Derkzen, D. M., Gobeil, R., and Gileno, J. 2009. "Visitation and Post-Release Outcome among Federally-Sentenced Offenders." Correctional Service of Canada. June. Retrieved from http://publications.gc.ca/collections/collection_2010/scc-csc/PS83-3-205-eng.pdf

Digard, L., diZerega, M., Yaroni, A., and Rinaldi, J. 2016. "A New Role for Technology: Video Visitation in Prison.” March. Vera Institute of Justice. February. Retrieved from www.vera.org/pubs/video-visitation-inprison

Dillman, D. A., Smyth, J. D., and Christian, L. M. 2009. Internet, Mail, and Mixed-Mode Surveys: The Tailored Design Method. Hoboken, NJ: John Wiley \& Sons.

Dixey, R. and Woodall, J. 2012. "The Significance of 'The Visit' in an English Category-B Prison: Views from Prisoners, Prisoners' Families and Prison Staff." Community, Work and Family 15 (1): 29-47. doi:10.1080/13668803.2011.580125. 
This is an author-produced, peer-reviewed version of this article. The final, definitive version of this document can be found online at Journal of Crime \& Justice, published by Taylor and Francis. Copyright restrictions may apply. https://doi.org/10.1080/0735648X.2019.1653216. The content of this document may vary from the final published version.

Duwe, G. and Clark, V. 2013. "Blessed be the Social Tie that Binds: The Effects of Prison Visitation on Offender Recidivism.” Criminal Justice Policy Review 24 (3): 271-296. doi:10.1177/0887403411429724.

Duwe, G. and Johnson, B. R. 2016. "The Effects of Prison Visits from Community Volunteers on Offender Recidivism.” The Prison Journal 96 (2): 279-303. doi:10.1177/0032885515618468.

Fulcher, P. A. 2014. "The Double Edged Sword of Prison Video Visitation: Claiming to Keep Families Together While Furthering the Aims of the Prison Industrial Complex." Florida AandM University Law Review 9 (1).

Grohs, M. 2013. "Video Visitation: Considerations about its Uses." Corrections Forum March/April: 26-30.

Hairston, C. F. 1991. "Family Ties During Imprisonment: Important to Whom and for What?" Journal of Sociology and Social Welfare 18 (1): 87-104.

Hairston, C. F. 1998. "The Forgotten Parent: Understanding the Forces that Influence Incarcerated Fathers' Relationships with their Children." Child Welfare 77 (5): 617-639.

Hensley, C., Kocheski, M., and Tewksbury, R. 2002. "Does Participation in Conjugal Visitations Reduce Prison Violence in Mississippi? An Exploratory Study." Criminal Justice Review 27 (1): 52-65. doi:10.1177/073401680202700104.

Hutton, M. 2016. "Visiting Time: A Tale of Two Prisons." Probation Journal 63 (3): 347-361. doi:10.1177/0264550516663644.

Jiang, S., Fisher-Giorlando, M., and Mo, L. 2005. "Social Support and Inmate Rule Violations: A Multilevel Analysis." American Journal of Criminal Justice 30 (1): 71-86. doi:10.1007/BF02885882.

Jiang, S., and Winfree, L. T. 2006. "Social Support, Gender, and Inmate Adjustment to Prison Life: Insights from a National Sample.” The Prison Journal 86 (1): 32-55. doi:10.1177/0032885505283876.

Johnson, C. E., and Hesse, T. H. 2005. "New Technology is Creating Improvements in the Corrections Field." Corrections Today 67 (4), 62-64.

Kaeble, D. and Cowhig, M. 2018. "Correctional Populations in the United States, 2016." Bureau of Justice Statistics. April 25. Retrieved from www.bjs.gov/content/pub/pdf/cpus16.pdf

Lawrence, A. 2017. "Justice Reinvestment: State Resources.” National Conference of State Legislatures. January 1. Retrieved from www.ncsl.org/research/civil-and-criminal-justice/justicereinvestment.aspx

Liu, S., Pickett, J. T., and Baker, T. 2014. "Inside the Black Box: Prison Visitation, the Costs of Offending, and Inmate Social Capital.” Criminal Justice Policy Review 27 (8): 766-790. doi:10.1177/0887403414562421.

Loper, A. B. and Coleman, E. S. 2014. "Video Visitation for Inmates: Thinking Outside of the Tiny Box." Corrections Today 76 (2): 54-59.

Mears, D. P., Cochran, J. C., Siennick, S. E., and Bales, W. D. 2012. "Prison Visitation and Recidivism.” Justice Quarterly 29 (6): 888-918. doi:10.1080/07418825.2011.583932.

Meyers, T. J., Wright, K. A., Young, J. T. N., and Tasca, M. 2017. "Social support from outside the walls: Examining the role of relationship dynamics among inmates and visitors." Journal of Criminal Justice 52: 57-67. doi:10.1016/j.jcrimjus.2017.07.012.

Mitchell, M. M., Spooner, Jia, D., and Zhang, Y. 2016. "The Effect of Prison Visitation on Reentry Success: A Meta-Analysis.” Journal of Criminal Justice 47 (C): 74-83. doi:10.1016/j.jcrimjus.2016.07.006.

Mowen, T. J. and Visher, C. A. 2016. "Changing the Ties that Bind: How Incarceration Impacts Family Relationships." Criminology and Public Policy 15 (2): 503-528. doi:10.1111/1745-9133.12207.

Phillips, S. D. 2012. "Video Visits for Children Whose Parents are Incarcerated: In Whose Best Interest?" The Sentencing Project. October 6. Retrieved from www.sentencingproject.org/publications/video-visits-forchildren-whose-parents-are-incarcerated-in-whose-best-interest/

Pierce, M. B. 2015. "Male Inmate Perceptions of the Visitation Experience: Suggestions on How Prisons can Promote Inmate-Family Relationships." The Prison Journal 95 (3): 370-396. doi:10.1177/0032885515587471.

Praetorius, R., Terry, L. F., and Burse, J. 2017. “'Thank You for Letting it Be About Me': Women's perceptions of holistic programming in a jail." Journal of Offender Rehabilitation 56 (4): 237-251. doi:10.1080/10509674.2017.1294639.

Rabuy, B. and Wagner, P. 2015. "Screening Out Family Time: The For-Profit Video Visitation Industry in Prisons and Jails." Prison Policy Initiative. January. Retrieved from www.prisonpolicy.org/visitation/report.html

Rogers, D. 2013. "The Surge in Video Visits: Is There a Trade Off? If So, Where is the Balance?" Corrections Forum 22 (6): 20-26.

Schubert, E. C., Duininck, M., and Shlafer, R. J. 2016. "Visiting Mom: A Pilot Evaluation of a Prison-Based Visiting Program Serving Incarcerated Mothers and their Minor Children." Journal of Offender Rehabilitation 55 (4): 213-234. doi:10.1080/10509674.2016.1159641. 
This is an author-produced, peer-reviewed version of this article. The final, definitive version of this document can be found online at Journal of Crime \& Justice, published by Taylor and Francis. Copyright restrictions may apply. https://doi.org/10.1080/0735648X.2019.1653216. The content of this document may vary from the final published version.

Siennick, S. E., Mears, D. P., and Bales, W. D. 2012. "Here and Gone: Anticipation and Separation Effects of Prison Visits on Inmate Infractions." Journal of Research in Crime and Delinquency 50 (3): 417-444. doi: $10.1177 / 0022427812449470$.

Sturges, J. E. 2002. "Visitation at County Jails: Potential Policy Implications." Criminal Justice Policy Review 13 (1): 32-45. https://doi-org.proxy.lib.sfu.ca/10.1177/0887403402131003.

Sturges, J. E. and A. M. Al-Khattar. (2009). "Survey of Jail Visitors about Visitation Policies." The Prison Journal 89 (4): 482-496. doi:10.1177/0032885509351009.

Tartaro, C. and Levy, M. P. 2017. "Visitation Modality Preferences for Adults Visiting Jails." The Prison Journal 97 (5): 562-584. doi:10.1177/0032885517728871.

Tasca, M. 2015. "The Gatekeepers of Contact: Child-Caregiver Dyads and Parental Prison Visitation.” Criminal Justice and Behavior 43 (6): 739-758. doi:10.1177/0093854815613528.

Tasca, M., Mulvey, P. and Rodriguez, N. 2016. "Families coming together in prison: An examination of visitation encounters." Punishment \& Society 18 (4): 459-478. doi:10.1177/1462474516642856.

Tewksbury, R. and DeMichele, M. 2005. "Going to Prison: A Prison Visitation Program.” The Prison Journal 85 (3): 292-310. doi:10.1177/0032885505279525.

Wagner, P. and Rabuy, B. 2017. "Following the Money of Mass Incarceration.” Prison Policy Initiative. January 25. Retrieved from www.prisonpolicy.org/reports/money.html

Wooldredge, J. D. 1997. "Explaining Variation in Perceptions of Inmate Crowding.” The Prison Journal 77 (1): 2740. doi:10.1177/0032855597077001003.

Wright, G. 2015. "An Empirical Examination of the Relationship between Nonresponse Rate and Nonresponse Bias." Statistical Journal of the IAOS 31: 305-315. doi:10.3233/SJI-140844. 